\title{
Effect of exopolysaccharide-producing strains of Streptococcus thermophilus on technological attributes of fat-free lassi
}

\author{
P. V. Behare,${ }^{* 1}$ R. Singh, ${ }^{*}$ S. K. Tomar, ${ }^{*}$ R. Nagpal, $\dagger$ M. Kumar, ${ }^{*}$ and D. Mohaniał \\ *Dairy Microbiology Division, National Dairy Research Institute, Karnal 132001, Haryana, India \\ †Department of Biotechnology, JMIT Institute of Engineering and Technology, Radaur 135133, Haryana, India \\ $\ddagger$ Animal Biochemistry Division, National Dairy Research Institute, Karnal 132001, Haryana, India
}

\begin{abstract}
Sixty-four exopolysaccharide-producing thermophilic lactic acid bacteria (LAB) were isolated from traditionally made Indian fermented milk products. On the basis of morphological and biochemical tests, these isolates were identified as the species of Lactobacillus, Streptococcus, and Enterococcus genera. Initial screening for technological attributes revealed that Streptococcus thermophilus IG16 was a promising isolate, and produced both capsular and ropy polysaccharides at the concentration of $211 \mathrm{mg} / \mathrm{L}$. Exopolysaccharide produced by IG16 was a heteropolysaccharide containing rhamnose and galactose in a ratio of 5.3:1 and had a molecular weight of $3.3 \times 10^{4}$ Da. Use of IG16 as a starter culture controlled whey separation and improved viscosity, flavor, consistency, and color and appearance of lassi. Use of IG16 resulted in lassi having optimal acidity, less syneresis, high viscosity, and better scores for flavor, consistency, and color and appearance.
\end{abstract}

Key words: lactic acid bacteria, Streptococcus thermophilus, exopolysaccharide, lassi

\section{INTRODUCTION}

Several lactic acid bacteria (LAB) produce extracellular polysaccharides, called exopolysaccharides (EPS), that improve physical, rheological, and sensory properties of fermented milk products (De Vuyst and Degeest, 1999; Folkenberg et al., 2006; Behare et al., 2009a,b). The EPS produced by LAB act as biothickeners, stabilizers, or gums and enhance mouthfeel of the products (De Vuyst et al., 2003; Ruas-Madiedo and de los Reyes-Gavilan, 2005). These polysaccharides either are excreted in the growth medium as slime/ropy polysaccharides or remain attached to the bacterial cell wall, thus forming capsular polysaccharides (Cerning, 1990). Besides improvement in technological properties of food products, some EPS produced by LAB showed beneficial effects on human health (Chabot et al., 2001; Korakli et al., 2002).

Received April 15, 2009.

Accepted February 25, 2010.

${ }^{1}$ Corresponding author: pradip_behare@yahoo.com
The EPS production by dairy LAB varies from strain to strain and is affected by several factors such as composition of the medium, age of the cell, $\mathrm{pH}$, and temperature (De Vuyst et al., 2003; Ruas-Madiedo and de los Reyes-Gavilan, 2005). The reported values for EPS production range between 25 and $9,800 \mathrm{mg} / \mathrm{L}$ (Smitinont et al., 1999; Van Geel-Schutten et al., 1999; Ruas-Madiedo et al., 2002; Bergmaier et al., 2003; Savadogo et al., 2004). It has been observed that the in situ EPS production by LAB contributes to the physicochemical and rheological properties of fermented milk products more than EPS powder added externally during fermentation of milk (Doleyres et al., 2005). The complex interactions between 3 components, namely EPS, EPS-producing bacterial cells, and milk proteins, are essential for texture build-up along with improvement of physicochemical and rheological properties (Doleyres et al., 2005; Behare et al., 2009b, c). Such interactions are not always observed in fermented milks prepared with addition of purified EPS powder. Lassi (a refreshing, drinkable, yogurt-like beverage popular in the Indian subcontinent) is prepared from milk with 1.5 to $4.5 \%$ fat after making a set curd product (i.e., dahi), followed by vigorous stirring to break the curd and addition of sugar syrup plus optional flavor. It is a white to creamy-white, viscous liquid with a sweetish, rich aroma and mild to medium acidic taste.

Consumer concern for healthy, natural, and lowcalorie foods has generated more demand in the market for fat-free or reduced-fat products. Lassi with low fat content can be looked upon as one such option with commercial viability. However, low-fat lassi has poor consistency and flat flavor and shows excessive whey separation (Khurana and Kanawjia, 2007). To tackle these problems, manufacturers traditionally use additives like stabilizers, gelling agents, and milk solids. However, these approaches restrict the acceptance of such products by consumers insisting on natural food with no or few additives. The alternative approach to such commercial additives is the use of EPS-producing LAB that act as natural biothickeners (Ruas-Madiedo and de los Reyes-Gavilan, 2005). The present study aimed to isolate and screen EPS-producing thermophil- 
ic LAB and use these strains to improve technological properties of fat-free lassi.

\section{MATERIALS AND METHODS}

\section{Isolation of EPS-Producing Thermophilic LAB}

A total of 44 dahi samples were collected from rural areas of Karnal city in the northwest of India. Thermophilic LAB were isolated by plating appropriate dilutions of dahi samples on milk agar (Mozzi et al., 2001) supplemented with glucose $(10 \mathrm{~g} / \mathrm{L})$ and yeast extract $(3.5 \mathrm{~g} / \mathrm{L})$ and incubating plates at $42^{\circ} \mathrm{C}$ for $72 \mathrm{~h}$.

\section{Identification and Technological Screening of LAB}

The EPS-producing thermophilic LAB isolates were identified by morphological and biochemical tests as described by Holzapfel and Schillinger (1992) and Cogan and Accolas (1995). Lactic acid bacteria were screened for technological attributes such as titratable acidity, viscosity, and body and texture in $10 \%$ reconstituted skim milk. Initially, milk was prepared by reconstituting skim milk powder $[10 \%$ (wt/vol)] in distilled water. All LAB isolates obtained were transferred in $10 \%$ reconstituted skim milk to carry out lactic fermentation and produce curd.

The promising isolate was further identified up to species level by biochemical tests and PCR. The cultures were maintained in milk containing $20 \%$ (wt/vol) glycerol at $-70^{\circ} \mathrm{C}$. For inoculum preparation, $1 \%$ of the frozen culture was propagated in M17 medium (Himedia, Mumbai, India) at $42^{\circ} \mathrm{C}$ for $24 \mathrm{~h}$.

\section{EPS Production and Characterization}

The EPS production by selected LAB strain was allowed in deproteinized whey (Rimada and Abraham, 2003) supplemented with $10 \mathrm{~g} / \mathrm{L}$ of glucose. The EPS from deproteinized whey was isolated by repetitive ethanol precipitation and purified by diethyl amino ethyl cellulose ion exchange chromatography (Behare et al., 2009b). The carbohydrate content of EPS was determined by Anthrone method (Southgate, 1991) and protein content was determined by Lowry's method (Lowry et al., 1951). The monosaccharide composition of isolated and purified EPS was determined by HPLC (Water 2487, Waters, Milford, MA) using a sugar pack I column $(300 \times 6.5 \mathrm{~mm})$ with refractive index detector using $100 \%$ water (HPLC grade) as mobile phase. The molecular weight of EPS was determined by gel filtration technique with Seralose 4B column (Behare et al., 2009b,c).

\section{Preparation of Lassi}

Lassi was prepared from nonfat dry milk (12\% TS) by fermenting milk with EPS-producing culture. The curd obtained was broken and sugar syrup $\left(53^{\circ} \mathrm{Bx}\right.$ at $20^{\circ} \mathrm{C}$ ) was added at the rate of $15 \%$ (wt/vol). The resultant mixture was homogenized in a mixer for $2 \mathrm{~min}$ to obtain lassi with uniform consistency. The control batch of lassi was prepared by using EPS-negative culture Streptococcus thermophilus NCDC 074.

\section{Analysis of Lassi for Technological Properties}

Titratable Acidity. Titratable acidity of lassi was determined by titration method (Indian Standards, 1960). Ten grams of lassi was diluted with equal volume of boiled water at $100^{\circ} \mathrm{C}$. A few drops of phenolphthalein indicator were added and titrated with $0.1 \mathrm{~N} \mathrm{NaOH}$ until the appearance of a light pink tinge. The titratable acidity was expressed as percentage lactic acid.

Whey Separation. Whey separation in lassi was determined by the method of Wacher-Rodarte et al. (1993) with slight modifications. Thirty grams of lassi was centrifuged at $1,553 \times g$ for $15 \mathrm{~min}$. Whey separation $(\%)$ was expressed as weight $(\mathrm{g})$ of expelled whey per $100 \mathrm{~g}$ of lassi.

Viscosity. Viscosity was measured at $25^{\circ} \mathrm{C}$ using a Contarves Rheomat/108 E/R coaxial cylinder viscometer (Mettler Toledo, Greifensee, Switzerland) in a manual mode with a suitable shear rate of $500 / \mathrm{s}$ and spindle (1'1) immersed to about one-third of the spindle length. The Rheomat was run using the above parameters and viscosity was noted after $30 \mathrm{~s}$.

Sensory Analysis. A panel of 7 judges performed the sensory evaluation by paired stimuli comparison method. The lassi samples were served in $250-\mathrm{mL}$ beakers. Sensory analysis of lassi was performed by following a 9-point hedonic scale for various parameters such as flavor, consistency, color and appearance, acidity, and sweetness.

\section{Statistical Analysis}

The data were analyzed by Systat software (version 6, Systat Software Inc., Chicago, IL). Means and standard error of the parameters were obtained and tested for significance between the cultures by one-way ANOVA.

\section{RESULTS}

\section{Isolation of $L A B$}

Thermophilic LAB that produced mucoid colonies on milk agar were randomly picked and transferred to 
sterilized skim milk. Total number of 64 EPS-producing LAB that belonged to Streptococcus (19), Lactobacillus (25), and Enterococcus (20) genus were isolated. All LAB cultures were subjected to technological screening (Table 1). Out of these genera, only Streptococcus was taken up for further study.

\section{Selection of Promising $L A B$}

Initial technological screening of streptococcal cultures revealed that the isolate designated as IG16 showed optimal acid production, high viscosity, low whey separation (observed visually), pleasant flavor, and good body and texture (Table 1). Species-specific biochemical and molecular tests identified IG16 as Streptococcus thermophilus.

\section{Characterization of EPS}

Exopolysaccharides productions vary from strain to strain (Table 2). Streptococcus thermophilus IG16 showed a large capsule surrounding the cell surface (Figure 1) and was able to produce higher amounts of EPS (211 mg/L) in deproteinized whey compared with other Streptococcus strains. However, it did not differ significantly with EPS produced by $S$. thermophilus IG11. Isolation of EPS from deproteinized whey by ethanol precipitation gave better yield of carbohydrate. Further purification of polymer by DEAE-cellulose ion exchange chromatography led to pure EPS with greater than $99.5 \%$ carbohydrate and a negligible amount of protein.

Results of HPLC revealed that EPS of $S$. thermophilus was heteropolysaccharides containing rhamnose and galactose in a ratio of 5.3:1. The molecular weight of IG16 EPS was approximately 33,000 Da.

\section{Effect of Thermophilic Culture on Technological Properties of Lassi}

Results of effect of EPS-producing thermophilic cultures on technological properties of lassi are depicted in Table 3. Titratable acidity of lassi differed significantly $(P<0.05)$ between the cultures. Both EPS-positive and EPS-negative cultures exhibited optimal acid production. However, IG16 showed higher titratable acidity as compared with S. thermophilus NCDC 074.

Whey separation in lassi differed significantly $(P$ $<0.05$ ) between EPS-positive and EPS-negative cultures. Streptococcus thermophilus IG16 binds significant amount of whey in lassi, which may be attributed to the production of EPS. The EPS-negative cultures were unable to control whey expulsion. Viscosity of lassi was tremendously increased by EPS-producing cultures.
The sensory scores for flavor, consistency, and color and appearance were significantly higher $(P<0.05)$ for lassi made with EPS-positive $S$. thermophilus IG16 than the control. The acidity and sweetness scores were found to be nonsignificant between the cultures. Flavor, consistency, and color and appearance scores of lassi tremendously increased with $S$. thermophilus IG16.

\section{DISCUSSION}

Use of suitable screening medium increases the probability of EPS-producing phenotypes (RuasMadiedo and de los Reyes-Gavilan, 2005; Behare et al., 2009b,c). Incorporation of a carbon source such as glucose in a milk agar medium increases the number of EPS-producing isolates. We could isolate a sufficient number of EPS-producing thermophilic LAB from village dahi, indicating that traditionally made fermented milk products are the reservoir for isolation of these cultures. Several reports have already been compiled on isolation of EPS-producing LAB from dairy- and non-dairy-based fermented foods from different regions of the world (Ludbrook et al., 1997; Smitinont et al., 1999; Sanni et al., 2002; Savadogo et al., 2004; Behare et al., 2009b,c).

To select commercially important cultures, only the Streptococcus group was taken up in our study. Streptococci have a technological edge over other cultures because they are fast growers and generally require a short period to set product. However, initial screening of EPS-producing culture is necessary because not all strains produce product with desirable attributes (De Vuyst et al., 2003; Behare et al., 2009b,c). Only S. thermophilus IG16 showed highest viscosity and promising attributes of fermented milk manufacture.

Streptococcus thermophilus IG16 produced capsular as well as ropy polysaccharides. Production of capsular or ropy polysaccharides is strain-dependent. Although the occurrence of 2 types of polysaccharides has been reported earlier (Ruas-Madiedo et al., 2002), comparative aspects of capsular polysaccharide or ropy polysaccharides in relation to functional properties of fermented milk product have not been clearly elucidated.

The EPS produced by $S$. thermophilus IG16 were heteropolysaccharides comprising of rhamnose and galactose. Production of particular monosaccharides by streptococci depends on the genetic potential of the strain (De Vuyst et al., 2003). The monosaccharides reported for $S$. thermophilus strains are rhamnose, galactose, glucose, and $N$-acetylgalactosamine (De Vuyst et al., 2003; Savadogo et al., 2004; Doleyres et al., 2005).

The molecular weight of a given polymer has been correlated with thickening properties of the fermented milk product, such that greater molecular weights are 
Table 1. Technological screening of lactic acid bacteria

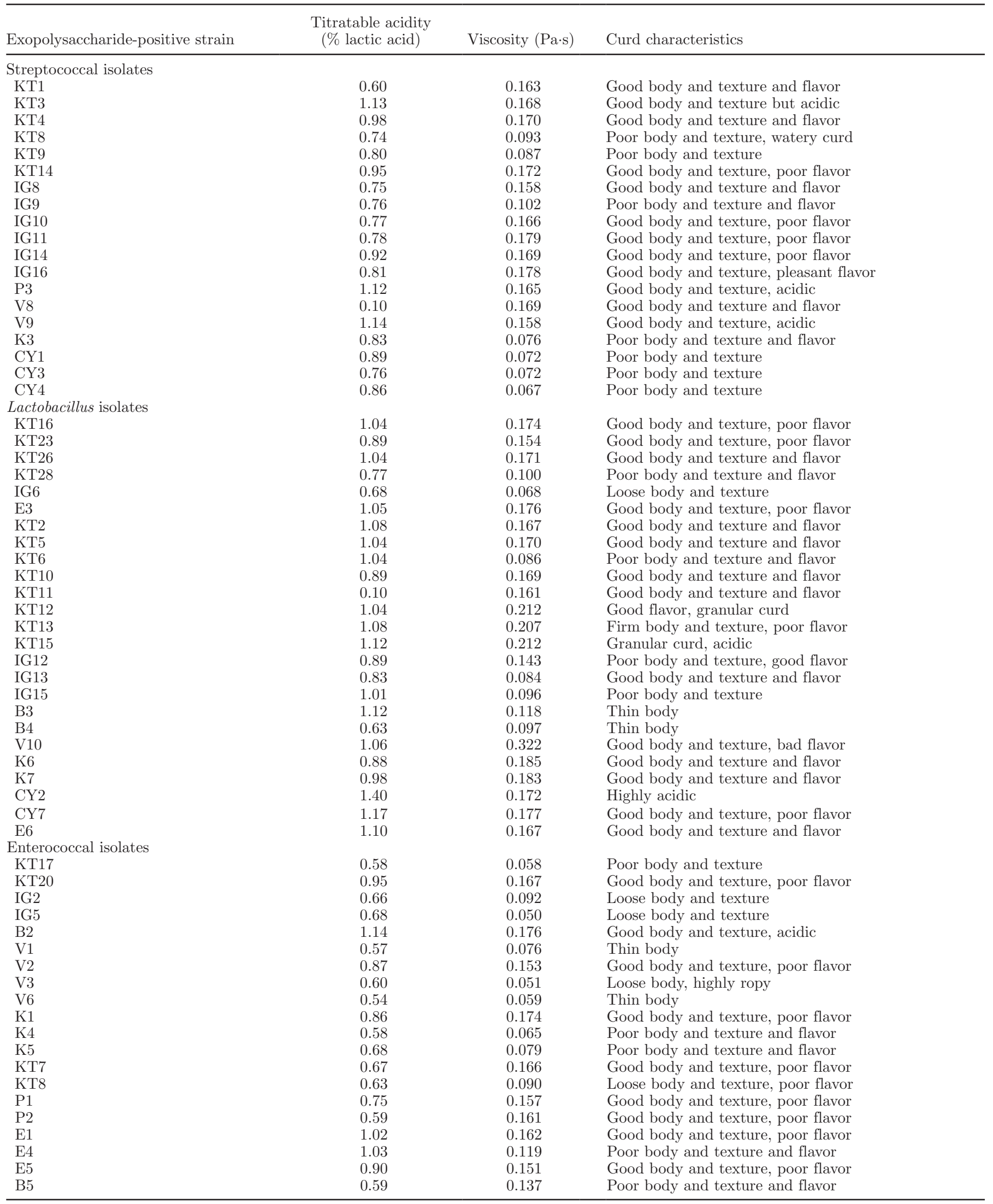


Table 2. Exopolysaccharide (EPS) production by streptococcal cultures

\begin{tabular}{lc}
\hline $\begin{array}{l}\text { Streptococcal } \\
\text { isolate }\end{array}$ & EPS $(\mathrm{mg} / \mathrm{L})$ \\
\hline KT1 & $176 \pm 2.08^{\mathrm{ab}}$ \\
KT3 & $190 \pm 0.88^{\mathrm{c}}$ \\
KT4 & $194 \pm 1.86^{\mathrm{c}}$ \\
KT8 & $132 \pm 1.20^{\mathrm{g}}$ \\
KT9 & $122 \pm 1.53^{\mathrm{h}}$ \\
KT14 & $196 \pm 2.03^{\mathrm{c}}$ \\
IG8 & $171 \pm 2.03^{\mathrm{a}}$ \\
IG9 & $152 \pm 1.76^{\mathrm{i}}$ \\
IG10 & $190 \pm 1.20^{\mathrm{c}}$ \\
IG11 & $207 \pm 1.73^{\mathrm{ef}}$ \\
IG14 & $199 \pm 0.58^{\mathrm{cd}}$ \\
IG16 & $211 \pm 1.54^{\mathrm{f}}$ \\
P3 & $181 \pm 2.08^{\mathrm{ab}}$ \\
V8 & $203 \pm 1.76^{\mathrm{de}}$ \\
V9 & $171 \pm 2.08^{\mathrm{a}}$ \\
K3 & $106 \pm 2.91^{\mathrm{j}}$ \\
CY1 & $93 \pm 1.54^{\mathrm{k}}$ \\
CY3 & $95 \pm 1.73^{\mathrm{k}}$ \\
CY4 & $77 \pm 2.19^{1}$ \\
\hline
\end{tabular}

${ }^{\mathrm{a}-\mathrm{l}}$ Means within a column with different superscripts differ significantly $(P<0.05)$.

associated with higher viscosity. The polymer produced by $S$. thermophilus IG16 had a molecular weight of 3.3 $\times 10^{4}$ Da. (Tuinier et al., 1999; Ruas-Madiedo et al., 2002; Behare et al., 2009b,c).

Exopolysaccharide-producing strains had a significant effect on physicochemical and sensory properties of lassi. Exopolysaccharides produced by $S$. thermophilus controlled whey separation in lassi because of its water binding ability. Similar results have been reported for various fermented milk products such as yogurt, dahi, and cultured buttermilk (Wacher-Rodarte et al., 1993; Marshall and Rawson, 1999; Doleyres et al., 2005; Behare and Prajapati, 2007; Behare et al., 2009b,c). High viscosity of lassi made by EPS culture indicated the possible role of EPS in imparting rheological and thickening properties as suggested in the literature (Marshall

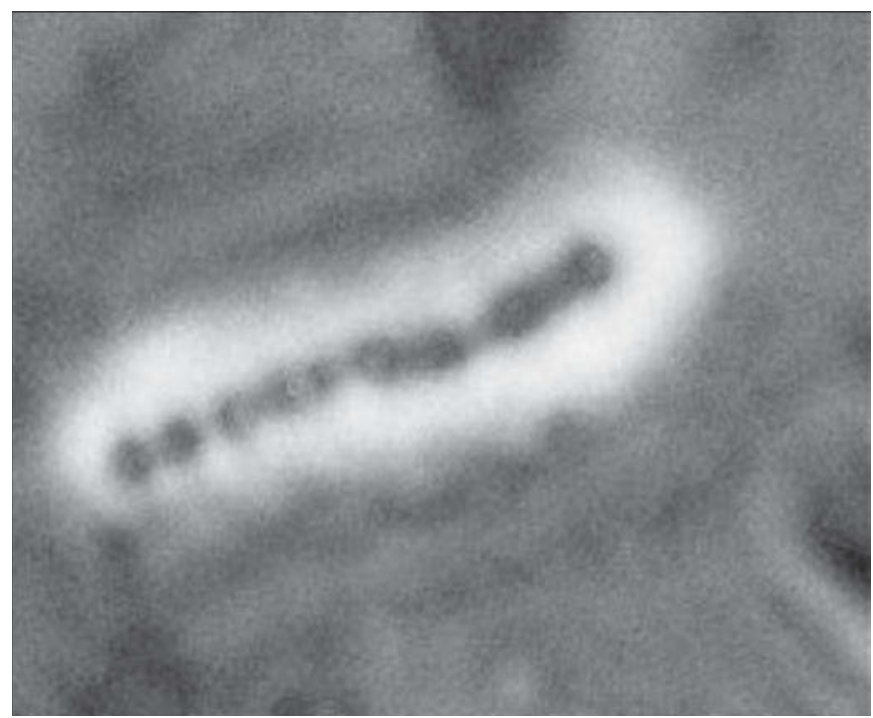

Figure 1. Capsule formation by Streptococcus IG16 isolate.

and Rawson, 1999). On the other hand, lassi made by EPS-negative culture was less viscous. Contribution of EPS to textural properties is a result of polymer and the ability of the polysaccharides to form strands that connect bacteria to the casein micelles. Use of EPS culture in lassi manufacture improved flavor, consistency, and color and appearance score. Earlier studies have reported that incorporation of EPS-positive strains increased mouth thickness and shininess of yogurt (Folkenberg et al., 2006).

To conclude, a novel EPS-producing strain of $S$. thermophilus has been isolated from traditionally made fermented milk that improved technological properties of fermented milk. Such a culture could be exploited commercially as a starter for making a variety of lowfat or fat-free fermented milk products.

Table 3. Technological properties of lassi ${ }^{1}$

\begin{tabular}{lccc}
\hline & Streptococcus thermophilus & Streptococcus thermophilus \\
Item & NCDC 074 & IG16 & SEM \\
\hline Titratable acidity (\% lactic acid) & $0.70 \pm 0.01^{\mathrm{a}}$ & $0.78 \pm 0.01^{\mathrm{b}}$ & $28 \pm 0.88^{\mathrm{b}}$ \\
Whey separation (\%) & $38 \pm 0.58^{\mathrm{a}}$ & $0.057 \pm 0.001^{\mathrm{b}}$ & $0.01^{* *}$ \\
Viscosity (Pa·s) & $0.047 \pm 0.02^{\mathrm{a}}$ & $7.67 \pm 0.24^{\mathrm{b}}$ & $0.00^{* *}$ \\
Flavor & $6.47 \pm 0.24^{\mathrm{a}}$ & $7.70 \pm 0.06^{\mathrm{b}}$ & $2.16^{*}$ \\
Consistency & $6.0 \pm 0.12^{\mathrm{a}}$ & $7.73 \pm 0.12^{\mathrm{b}}$ & $4.34^{* *}$ \\
Color and appearance & $7.20 \pm 0.12^{\mathrm{a}}$ & $6.78 \pm 0.09^{\mathrm{a}}$ & $0.43^{*}$ \\
Acidity & $6.64 \pm 0.10^{\mathrm{a}}$ & $6.80 \pm 0.06^{\mathrm{a}}$ & $0.08^{\mathrm{NS}}$ \\
Sweetness & $6.79 \pm 0.07^{\mathrm{a}}$ & $0.001^{\mathrm{NS}}$ \\
\hline
\end{tabular}

\footnotetext{
${ }^{\mathrm{a}, \mathrm{b}}$ Means within a row with different superscripts differ significantly $(P<0.05)$.

${ }^{1}$ Sensory scores are out of 9 points $(9=$ like extremely; $1=$ dislike $)$.

*Significant at $1 \%$; **ignificant at $5 \%$.
} 


\section{REFERENCES}

Behare, P. V., and J. B. Prajapati. 2007. Thermization as a method for enhancing the shelf-life of cultured butter milk. Indian J. Dairy Sci. 60:86-93.

Behare, P. V., R. Singh, M. Kumar, J. B. Prajapati, and R. P. Singh. 2009a. Exopolysaccharides of lactic acid bacteria: A review. J. Food Sci. Technol. 46:1-11.

Behare, P. V., R. Singh, R. Nagpal, M. Kumar, S. K. Tomar, and J. B. Prajapati. 2009c. Comparative effect of exopolysaccharides produced in situ or added as bioingredients on dahi properties. Milchwissenschaft 64:396-400.

Behare, P., R. Singh, and R. P. Singh. 2009b. Exopolysaccharideproducing lactic cultures for preparation of fat-free dahi-An Indian fermented milk. J. Dairy Res. 76:90-97.

Bergmaier, D., C. P. Champagne, and C. Lacroix. 2003. Exopolysaccharide production during batch cultures with free and immobilized Lactobacillus rhamnosus RW-9595 M. J. Appl. Microbiol. 95:1049-1057.

Cerning, J. 1990. Extracellular polysaccharides produced by lactic acid bacteria. FEMS Microbiol. Rev. 87:113-130.

Chabot, S., H. L. Yu, L. L. De, D. Cloutier, M. R. van Calsteren, M. Lessard, D. Roy, M. Locroix, and D. Oth. 2001. Exopolysaccharides from Lactobacillus rhamnosus RQ-595M stimulate TNF, IL-6 and IL-12 in human and mouse cultured immuno-competent cells, and IFN-g in mouse splenocytes. Lait 81:683-697.

Cogan, T. M., and J. P. Accolas. 1995. Dairy Starter Cultures. VCH Publishers, New York, NY.

De Vuyst, L., and B. Degeest. 1999. Heteropolysaccharides from lactic acid bacteria. FEMS Microbiol. Rev. 23:153-177.

De Vuyst, L., M. Zamfir, F. Mozzi, T. Adriany, V. Marshall, B. Degeest, and F. Vaningelgem. 2003. Exopolysaccharide-producing Streptococcus thermophilus strains as functional starter cultures in the production of fermented milks. Int. Dairy J. 13:707-717.

Doleyres, Y., L. Schaub, and C. Lacroix. 2005. Comparison of the functionality of exopolysaccharides produced in situ or added as bioingredients on yogurt properties. J. Dairy Sci. 88:4146-4156.

Folkenberg, D. M., P. Dejmek, A. Skriver, and R. I. Guldager. 2006. Sensory and rheological screening of exopolysaccharide producing strains of bacterial yogurt cultures. Int. Dairy J. 16:111-118.

Holzapfel, W. H., and V. Schillinger. 1992. The genus Leuconostoc. Pages 1509-1534 in The Prokaryotes. A. Barlows and H. G. Truper, ed. Springer, Berlin, Germany.

Indian Standards. 1960. IS: 1479. Methods of testing for dairy industry. Part I. Rapid examination of milk. Indian Standards Institution, New Delhi, India.

Khurana, H., and S. K. Kanawjia. 2007. Recent trends in development of fermented milks. Curr. Nutr. Food Sci. 3:91-108.

Korakli, M., A. Rossmann, M. G. Ganzle, and R. F. Vogel. 2002. Metabolism by bifidobacteria and lactic acid bacteria of polysaccharides from wheat and rye and exopolysaccharides produced by Lactobacillus sanfranciscensis. J. Appl. Microbiol. 92:958-965.
Lowry, O. H., N. J. Rosebrough, A. L. Farr, and R. J. Randal. 1951. Protein measurement with the folin phenol reagent. J. Biol. Chem. 193:265-275

Ludbrook, K. A., C. M. Russel, and R. I. Greig. 1997. Exopolysaccharide production from lactic acid bacteria isolated from fermented food. J. Food Sci. 62:597-600.

Marshall, V. M., and H. L. Rawson. 1999. Effect of exopolysaccharideproducing strains of thermophilic lactic acid bacteria on the texture of stirred yogurt. Int. J. Food Sci. Technol. 34:137-143.

Mozzi, F., M. Torino, and G. de Valdez. 2001. Identification of Exopolysaccharide-Producing Lactic Acid Bacteria: A Method for the Isolation of Polysaccharides in Milk Cultures. F. T. Spencer, and R. D. Spencer, ed. Humana Press, Totowa, NJ.

Rimada, P. S., and A. G. Abraham. 2003. Comparative study of different methodology to determine the exopolysaccharides produced by kefir grains in milk and whey. Lait 83:79-87.

Ruas-Madiedo, P., and C. G. de los Reyes-Gavilan. 2005. Invited review: Methods for the screening, isolation, and characterization of exopolysaccharides produced by lactic acid bacteria. J. Dairy Sci. 88:843-856.

Ruas-Madiedo, P., R. Tuinier, M. Kanning, and P. Zoon. 2002. Role of exopolysaccharides produced by Lactococcus lactis ssp. cremoris on the viscosity of fermented milks. Int. Dairy J. 12:689-695.

Sanni, A. I., A. A. Onilude, S. T. Ogunbanwo, H. F. Fadahunsi, and R. O. Afolabi. 2002. Production of exopolysaccharide by lactic acid bacteria isolated from traditional fermented foods in Nigeria. Eur. Food Res. Technol. 214:405-407.

Savadogo, A., C. A. T. Ouattara, P. W. Savadogo, N. Barro, A. S. Ouattara, and A. S. Traore. 2004. Identification of exopolysaccharides-producing lactic acid bacteria from Burkino Faso fermented milk samples. Afr. J. Biotechnol. 3:189-194.

Smitinont, T., C. Tansakul, S. Tanasupawat, S. Keeratipibul, L. Navarini, M. Bosco, and P. Cescutti. 1999. Exopolysaccharideproducing lactic acid bacteria strains from traditional Thai fermented foods: Isolation, identification and exopolysaccharides characterization. Int. J. Food Microbiol. 51:105-111.

Southgate, D. A. T. 1991. Selected methods. Pages 99-144 in Determination of Food Carbohydrates. D. A. T. Southgate, ed. Elsevier, London, UK.

Tuinier, R., P. Zoon, C. Olieman, M. A. Cohen-Stuart, G. J. Fleer, and C. G. de Kruif. 1999. Isolation and physical characterization of an exocellular polysaccharide. Biopolymers 49:1-9.

Van Geel-Schutten, G. H., E. J. Faber, E. Smith, K. Bonting, M. R. Smith, B. Brink, J. P. Kamerling, J. F. G. Vliegenthart, and L. Dijkhuizen. 1999. Biochemical and structural characterization of the glucan and fructan exopolysaccharides synthesized by Lactobacillus reuteri wild-type strain and by mutant strains. Appl. Environ. Microbiol. 65:3008-3014.

Wacher-Rodarte, C. M., M. V. Galvan, A. Farres, F. Gallardo, V. M. E. Marshall, and M. Garcia-Garibay. 1993. Yogurt production from reconstituted skim milk powders using different polymer and non-polymer forming starter cultures. J. Dairy Res. 60:247-254. 